$\begin{array}{cc}\text { ACADEMIA ROMÂNĂ } & \text { Rev. Roum. Chim., } \\ \mathbf{2 0 2 1}, \text { 66(2), 185-192 }\end{array}$

Dedicated to Professor Alexandru T. BALABAN on the occasion of his $90^{\text {th }}$ anniversary

\title{
DYE REMOVAL FROM WASTEWATERS USING GRAPE SEED RESIDUES
}

\author{
Robert ȚINCU, ${ }^{\mathrm{a}, \mathrm{b}}$ Cristina TODAŞCĂ ${ }^{\mathrm{a},{ }^{*}}$ Victoria ARTEM ${ }^{\mathrm{c}}$ and Adrian-Ionuț NICOARĂ $\breve{\mathrm{a}}^{\mathrm{a}, \mathrm{d}}$ \\ ${ }^{\text {a }}$ Faculty of Applied Chemistry and Materials Science, University POLITEHNICA of Bucharest, 1-7 Gh. Polizu Street, \\ 011061 Bucharest, Roumania \\ „ „C.D. Nenitescu” Institute of Organic Chemistry, Romanian Academy, 202B Spl. Independentei, 060023 Bucharest, Roumania \\ ${ }^{\mathrm{c}}$ Research Centre for Viticulture and Enology Murfatlar (RCVE), 2 Calea Bucureşti Street, Murfatlar, Constanta, Roumania \\ ${ }^{\mathrm{d}}$ National Centre for Micro and Nanomaterials, University POLITEHNICA of Bucharest, 313 Spl. Independentei, \\ 060042 Bucharest, Roumania
}

Received October 4, 2020

Dye removal from industrial wastewaters is a constant concern in industry, like textile or paper, since the consumers demands are in continuous increase and new dye combinations are developed and used. Therefore, efficient, and environmentally friendly dye adsorbents are a continuous necessity. This research aims to characterize the absorbents capacities of grapeseed material (rest material after grapeseed oil extraction). Apart from adsorbent characterization, the influence of contact time, adsorbent quantity and the influence of the solution $\mathrm{pH}$ are investigated. Following the principles of sustainability and circular economy, the transformation of by-products during the process of obtaining grapeseed oil into a usable absorbent material could resolve two major issues in two of the largest industries: wine industry waste management and removal of dyes from the textile industry wastewater.

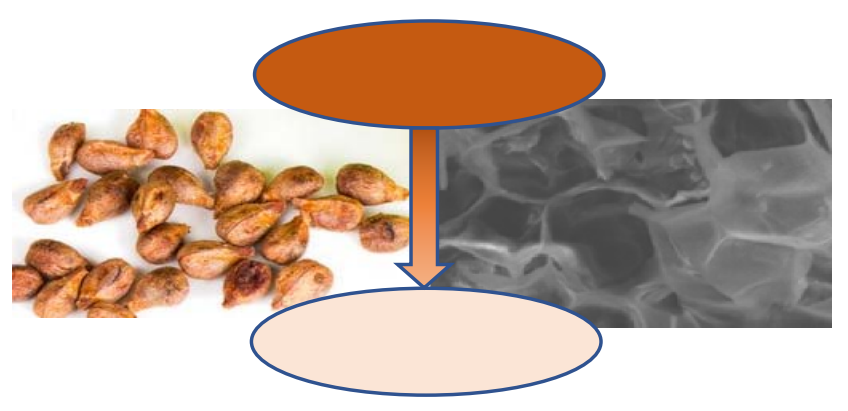

\section{INTRODUCTION}

Synthetic dyes are compounds that can be found in our daily lives and are widely used in various areas, such as the textile and paper industries. ${ }^{1}$ Over time, various research groups have shown that, when these synthetic dyes dissipate into the water, they create a series of negative effects on the environment, like reducing the rate of photosynthesis or having mutagenic and carcinogenic effects. ${ }^{2}$ The largest contributor to the amount of dyes found in residual water with reported effects harmful to human life, is considered the textile industry. ${ }^{3,4}$ For this reason, there has been a growing number of researches towards the development of novel methods to separate these synthetic dyes from the wastewater of industrial production. ${ }^{5-7}$ These methods can be classified as chemical, biological or physical. ${ }^{8}$ Among the possible methods, adsorption (physical) is the most convenient due to the numerous advantages, such as: high efficiency for all types of dyes and the absence of toxic by-products. ${ }^{9}$ The main disadvantage of this method is the high cost

\footnotetext{
*Corresponding author: cristina.todasca@upb.ro
} 
of adsorbents, but this becomes less of an issue, due to new adsorbents being produced from cheaper materials. ${ }^{10,11}$ Among the best source of cheap adsorbent materials include agricultural byproducts (plants, fruits) ${ }^{12-15}$ as they are available in large quantities, have little to no economic value and easily discarded, and do not pose supplementary toxic effects to the environment. ${ }^{16}$

According to the 2019 Statistical Report on World Vitiviniculture ${ }^{17}$ published by the International Organization of Vine and Wine (OIV), Romania ranks $10^{\text {th }}$ on a global level in terms of the surface area used for cultivating vines, ranks $5^{\text {th }}$ on the European level in terms of grape production (1.3 million tons in 2018), and ranks $6^{\text {th }}$ in terms of wine production (5.1 hectoliters in 2018). During grape processing for wine production, grape seeds and peals are obtained. These by-products represent $38-52 \%$ of the grape's mass. The grape seeds are mainly used to obtain grapeseed oil which represents $10 \%$ of the seed's mass, containing high levels of unsaturated fats. ${ }^{18}$ Grapeseed oil is considered a high-value product that has diverse uses and benefits for humans. ${ }^{19}$ Moreover, this can be used as a hydrating agent or anti-acne components in cosmetic products, and even as potential biodiesel. ${ }^{20}$ Once the grapeseed oil is extracted, the rest material represents a good source of natural adsorbents. ${ }^{21}$ This material was used before without further modifications by Vanni et al. ${ }^{22}$ to remove brilliant blue and amaranth red, two dyes used in the pharmaceutical industry, from aqueous solutions. Moreover, Afsharnia et al. ${ }^{23}$ transformed the rest material into an activated carbon able to remove reactive black 5 from aqueous solution. Therefore, this study aims to further characterize the absorbent capacities of this rest material. Following the principles of sustainability and circular economy, the transformation of by-products during the process of obtaining grapeseed oil into a usable absorbent material could resolve two major issues in two of the largest industries: wine industry waste management and removal of dyes from the textile industry wastewater.

\section{EXPERIMENTAL}

\section{Materials}

In this paper, the grape seeds used were Fetească Neagră, cultivated from INCDI Murfatlar in the autumn of 2017, and air-dried in a laboratory before the grape seed oil extraction. The dye used for the study was methyl orange, an azoic anionic dye also known as acid orange 52 .

\section{Methods}

The morphology and porosity of the material were evaluated through scanning electron microscopy using a Quanta Inspect F50 FEG (field emission gun) microscope with $1.2 \mathrm{~nm}$ resolution, equipped with an energy-dispersive X-ray (EDX) analyzer (resolution of $133 \mathrm{eV}$ at $\mathrm{MnK}$ ) on sample covered with a thin gold layer. The particle distribution analysis was done by measuring up to 200 particles on the SEM images taken from different parts of the sample to ensure good homogeneity.

Infrared spectra of the grape seeds were registered using a Bruker Equinox 55 spectrometer. The spectrometer uses the sampling technique called attenuated total reflectance (ATR), equipped with a selenium crystal, within a spectral window between $4000-650 \mathrm{~cm}^{-1}$. The recording of the spectra was done with the help of a computer and using the OPUS 5.5 program. Thus, the parameters necessary for the analysis (FTIR-ATR) were introduced and then the reference was saved. Initially, the background was recorded without introducing the sample, then the sample was placed directly on the ATR analyzer, so that a homogeneous layer was formed over the selenium crystal, allowing a correct recording of the IR spectrum.

Dye concentration during the adsorption process was measured using UV-Vis spectroscopy. The UV-Vis instrument used is an $\beta$ Helios ThermoFisher spectrometer, having an optic window between $400-800 \mathrm{~nm}$ and polystyrene cuvettes, with optical path of $1 \mathrm{~cm}$.

\section{Adsorbent developing}

Grape seed oil extraction was achieved according to the standard method described in SR EN ISO 659:2003. Grape seeds were ground and subjected to Soxhlet extraction with petroleum ether $\left(40-60^{\circ} \mathrm{C}\right.$ fraction), for $6 \mathrm{~h}$. After evaporation of the solvent from the liquid phase, the grape seed oil is obtained. The solid grape seed waste left in the extraction cartridge is dried and used directly, as absorbent, to remove dyes from wastewater without further processing.

\section{Adsorption experiments}

Adsorption experiments were carried out in an Erlenmeyer flask, at constant stirring speed and room temperature. In all the experiments the volume of the solution was $25 \mathrm{~mL}$ and the initial dye concentration was $0.03 \mathrm{mg} / \mathrm{mL}$.

\section{RESULTS AND DISCUSSION}

\section{Adsorbent characterization}

Figure 1 A shows an SEM-type micrograph of the grape seed before Soxhlet extraction. It can be noticed that the surface has a continuous aspect and the presence of fat particles is obvious.

On the other hand, the SEM micrograph (Figure 1 B) of solid waste highlights a network of pores of approximately the same shape and size, characteristic for the Fetească Neagră variety. 

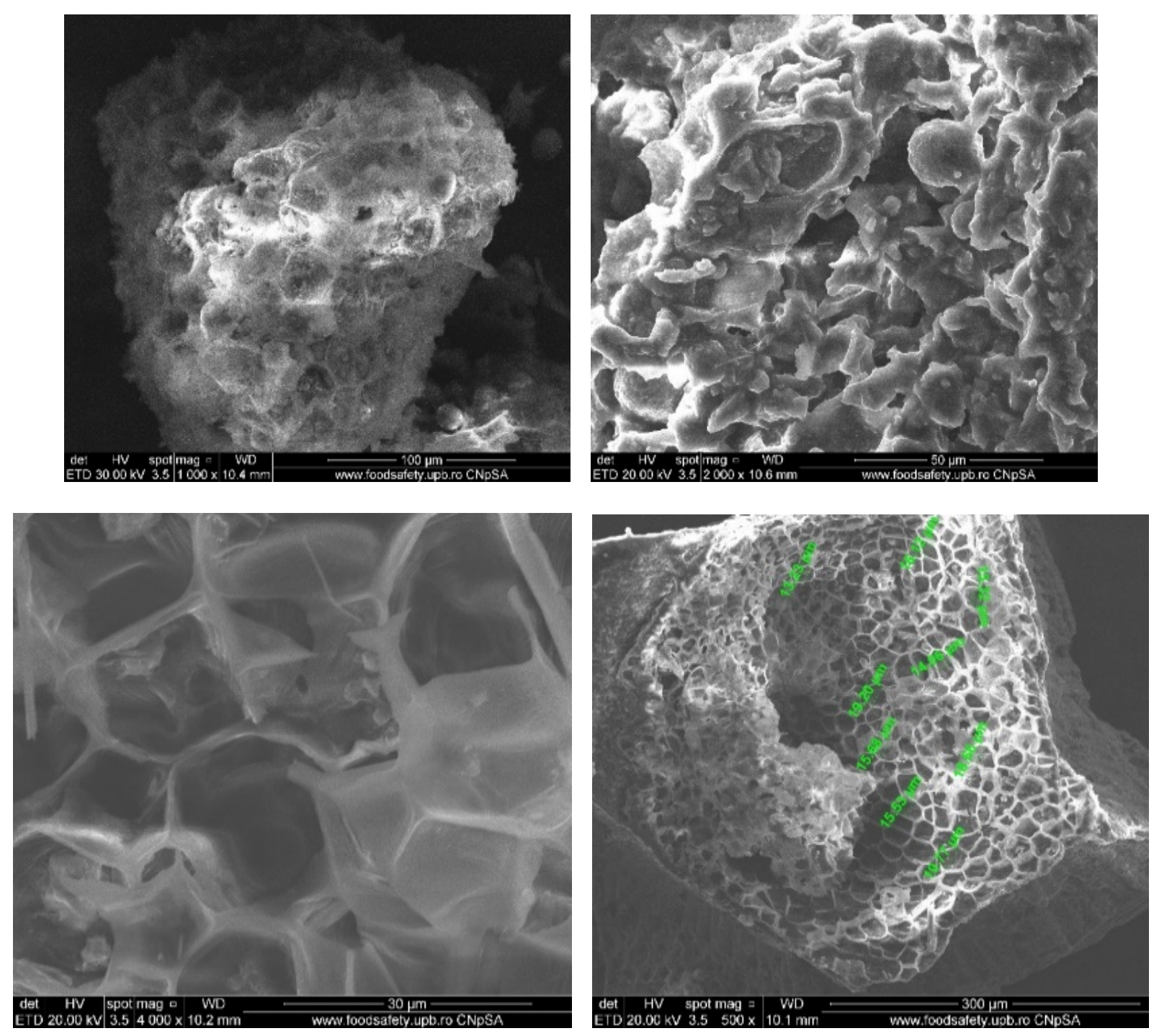

Fig. 1 - SEM micrograph of Fetească Neagră grape seeds before (A) and after (B) extraction.

EDX analysis (Figure 2) confirms the presence of main elements specific to the material which are carbon and oxygen. In addition to these two elements, it can be seen that the adsorbent also contains small amounts of calcium and potassium. The appearance of gold atoms at higher voltages is due to the method of sample preparation, the EDX analysis being coupled with the SEM analysis.

The particle distribution presented in Figure 2 shows that the particles are located mainly in the range $0-250 \mu \mathrm{m}$ with an average size of 196.47 micrometers.

Figure 3 compares the IR spectra of a grape seed sample before adsorption (a), after adsorption (b) and dye (c). There are no big differences between the IR spectra of the adsorbent before and after adsorption because the experiments were performed at high dilutions and therefore no quantitative conclusions can be drawn using this technique. This analysis proves that the dye was entrapped in the pores of the material and therefore the IR analysis of the material surface will show little to no dye on the grape seed surface.

However, by extending the spectral region between $2000 \mathrm{~cm}^{-1}$ and $1400 \mathrm{~cm}^{-1}$ (Figure 4), one can observe the appereance and intensification of some bands, notably the apparition of a band at ca. $1600 \mathrm{~cm}^{-1}$ (characteristic for the C-C stretching into the aromatic nucleus) and the enhancement of the consortium of absorption bands at ca. $1450 \mathrm{~cm}^{-1}$ (methyl groups bending). On the other hand, the bands characteristic to the azo moiety $(-\mathrm{N}=\mathrm{N}-)$, as well as the $-\mathrm{SO}_{3} \mathrm{H}$ group are not visible. This could probably indicate an ionic type of interaction between the seeds surface and the dye. This confirms that the dye molecules interacted with the adsorbent material and that half of the molecule "the one with the $\mathrm{HSO}_{3}-\mathrm{Ph}-\mathrm{N}=\mathrm{N}$ - part" being entrapped in the seeds surface pores. 


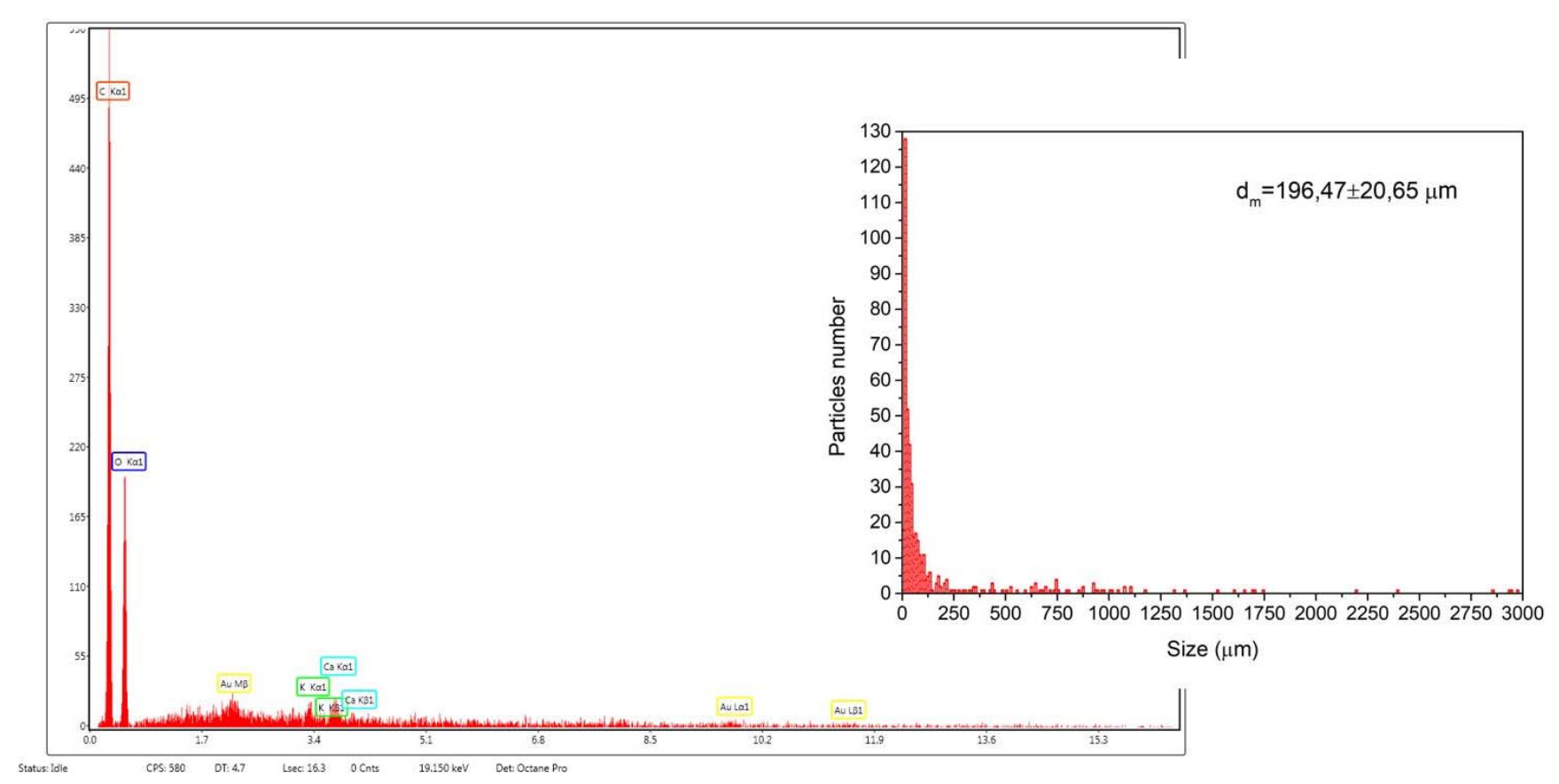

Fig. 2 - EDX spectra and particle size distribution.

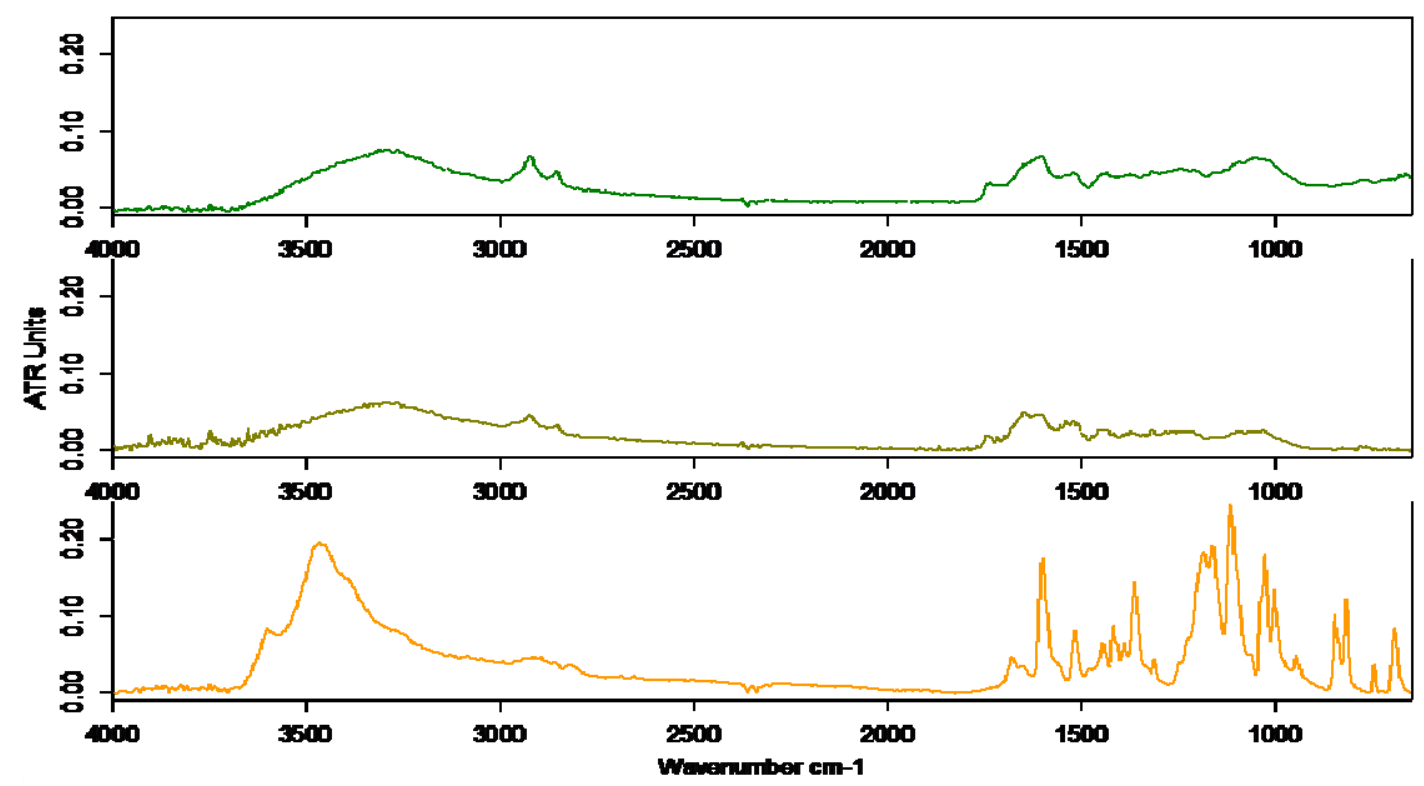

Fig. 3 - FTIR spectra of grapeseed adsorbent (a); grapeseed after extraction of methyl orange (b); methyl orange (c).

\section{Influence of contact time}

One important factor regarding dye removal from wastewater is the contact time between the adsorbent and the treated water. To determine the influence of contact time on the efficiency of the adsorption process, solutions of $\mathrm{pH}=7$ of methyl orange of the same concentration $(0.03 \mathrm{mg} / \mathrm{mL})$ were prepared, in which the same amount of adsorbent $(10 \mathrm{mg} / \mathrm{mL})$ was added, but the contact time was varied between 5 and 120 minutes. 


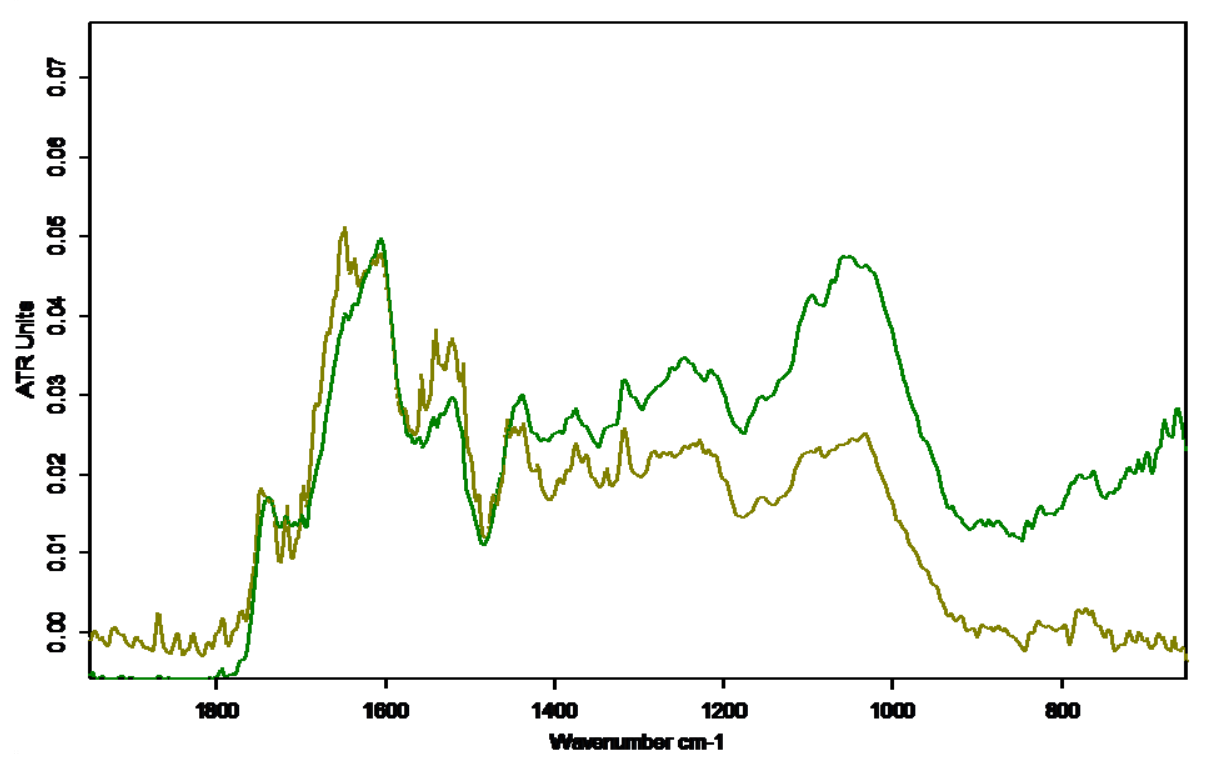

Fig. 4 - Detail of FT-IR spectra (area 2000-600 $\mathrm{cm}^{-1}$ ).

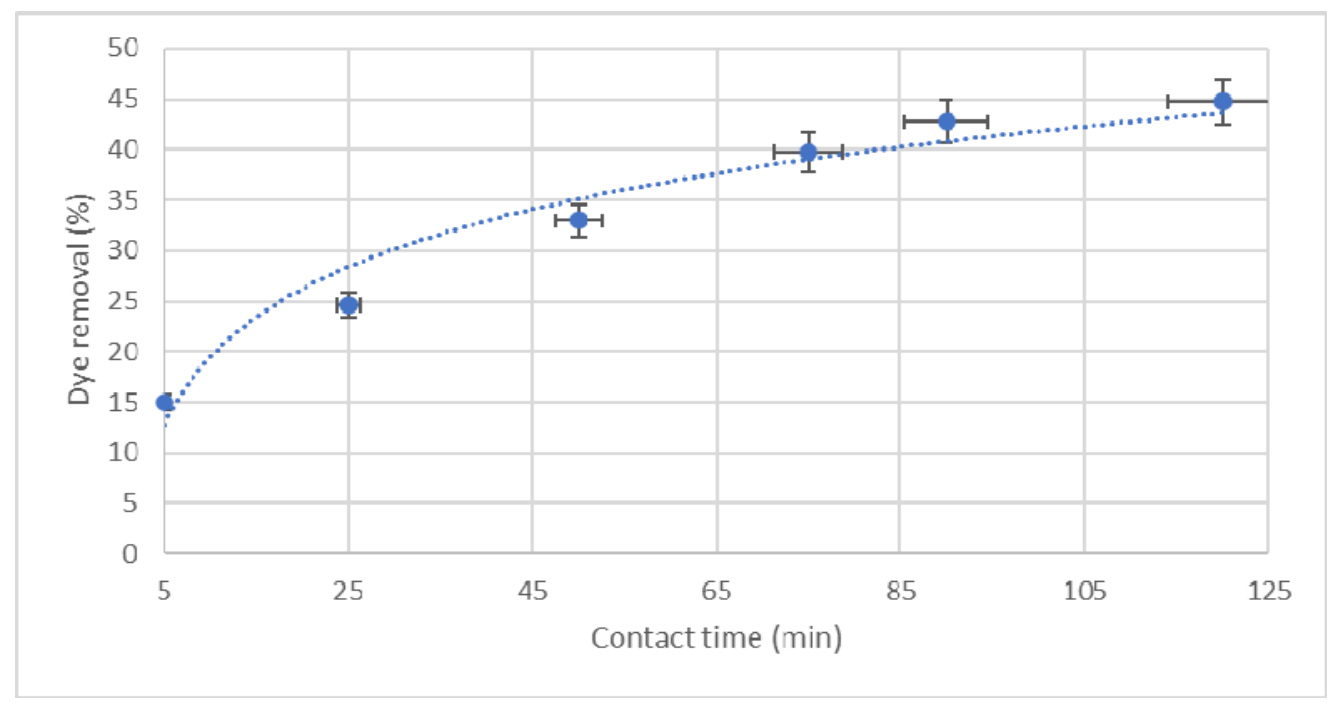

Fig. 5 - Influence of contact time.

In Figure 5 it can be noticed that as the contact time between the adsorbent and the dye solution increases, the percentage of dye removal also increases. On the other hand, the speed with which this percentage is increasing is quite slow and in time is reaching equilibrium, which can be graphically represented as a level. This balance begins to be established in the case of grape seed adsorbent after more than 120 minutes, when the dye is removed in a proportion of $45-50 \%$.

\section{Influence of adsorbent concentration}

Another important factor when the removal of dye from wastewater is considered, is the optimal ratio between the adsorbent material and the concentration of the dye in the wastewater. To determine the influence of the amount of adsorbent on the adsorption process, in Erlenmeyer flasks, 25 $\mathrm{mL}$ of neutral methyl orange solution of the same concentration $(0.03 \mathrm{mg} / \mathrm{mL})$ and a variable amount of adsorbent was added, ranging from $0.1 \mathrm{~g}$ and $0.6 \mathrm{~g}$. For this experiment, the contact time was kept constant (10 minutes).

In Figure 6 it can be seen that as the amount of adsorbent increases from $0.1 \mathrm{~g}$ to $0.6 \mathrm{~g}$ and the removal percentage of methyl orange increases from about $16 \%$ to about $40 \%$. However, the percentage of adsorbed dye does not increase linearly with the amount of adsorbent, but as the concentration of adsorbent material increases, its use becomes less and less efficient. 

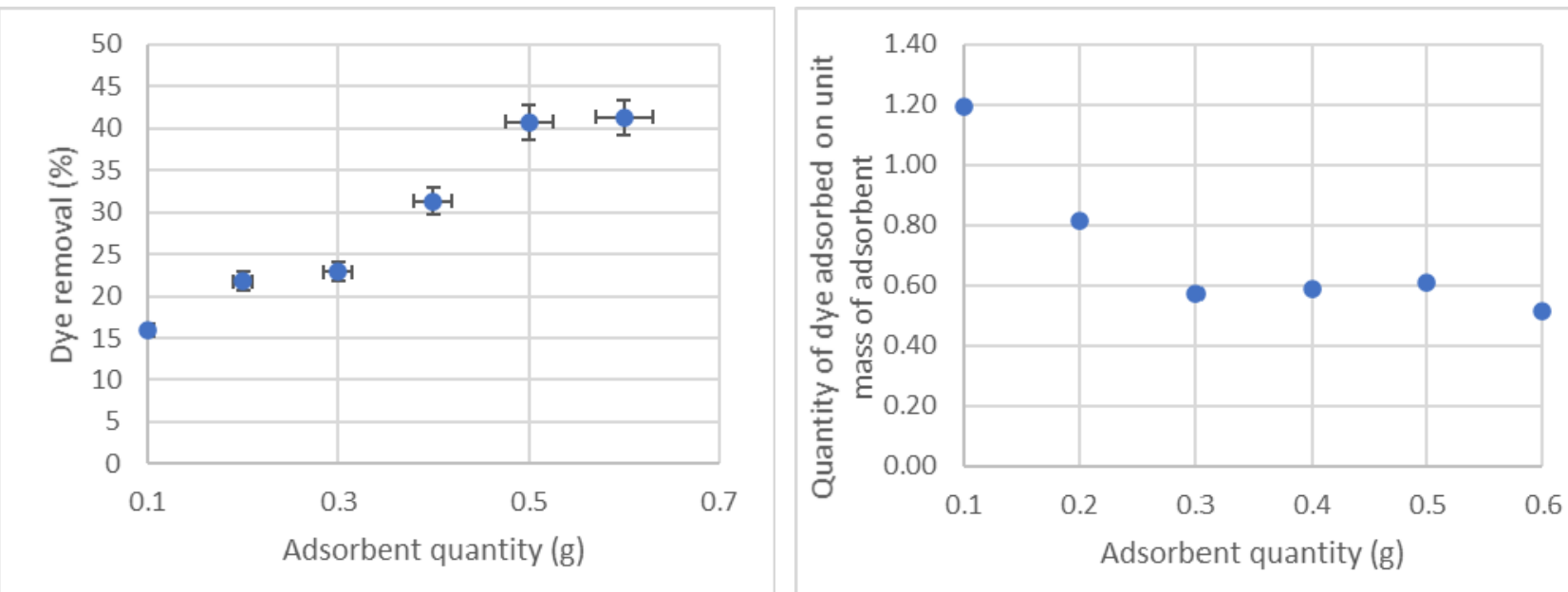

Fig. 6 - Influence of adsorbent quantity on dye removal.

Figure 6 shows the amount of dye adsorbed, relative to the unit mass of adsorbent material. A decrease of this ratio is observed from 1.19 in the case of using the adsorbent in the amount of $0.1 \mathrm{~g}$, to 0.52 in the case of using $0.6 \mathrm{~g}$ of adsorbent. These variations are explained by the increase in the number of active centers and therefore the possibility of adsorption of dye molecules on several particles of grape seeds.

Therefore, the optimal amount of adsorbent to be used is between $0.2-0.3 \mathrm{~g}$ per $25 \mathrm{~mL}$ of $0.03 \mathrm{mg} / \mathrm{mL}$ of neutral methyl orange solution, which ensures an acceptable degree of dye removal, and at the same time an efficient use of the adsorbent.

\section{Influence of $\mathrm{pH}$}

To determine how the $\mathrm{pH}$ influences the adsorption of methyl orange, a dye solution of $\mathrm{pH}=1$ and concentration $0.03 \mathrm{mg} / \mathrm{mL}$ was prepared, and the adsorbent was added in a concentration of $10 \mathrm{mg} / \mathrm{mL}$. The dye concentration was monitored for 40 minutes.

Figure 7 shows data obtained at $\mathrm{pH}=1$, compared to the results obtained under the same working conditions at neutral $\mathrm{pH}$. In the case of acidic $\mathrm{pH}$, the binding of the dye is much more efficient compared to the neutral working conditions. The adsorption process is better at acidic $\mathrm{pH}$ and faster, because the balance is established after about 20 minutes, compared to 120 minutes. This is because methyl orange is an anionic dye, and therefore its affinity for the adsorbent increases as the $\mathrm{pH}$ decreases, due to the loading of the interface with positive charges.

\section{Stepwise dye removal}

Since the adsorbent can extract only partially the dye from the wastewater $(45-55 \%)$ in one step, a step by step dye removal was investigated. Therefore, a methyl-orange solution, of initial concentration of $0.03 \mathrm{mg} / \mathrm{mL}$, was removed from the water in four steps, with each step having a contact time of 10 minutes and using an adsorbent concentration of $10 \mathrm{mg} / \mathrm{mL}$. The results obtained after each step are illustrated in Figure 8.

It can be noticed that the results of this dye removal method are remarkable compared to other experiments presented above, since only after 40 minutes, the dye was removed $75 \%$, whereas in the best working conditions $(\mathrm{pH}=1)$ and with the same contact time, the percentage of removal was approximately $55 \%$.

On the other hand, it can be observed that the variation of concentration over time (and implicitly the number of steps taken) follows a decreasing exponential function with a tendency of flattening after 40 minutes, showing that the total removal (or up to a sufficient level so low as not to pose any danger) of the dye would require an even greater number of stages of removal. Therefore, it can be concluded that the stepwise removal of dyes could be used as a pre-treatment of wastewater, after which the dye disappears completely in other working conditions which may require costly methods.

This method reduces the financial effort required to purify wastewater from the textile industry to a maximum of $25 \%$ of total costs. In this way, the procedure for disposing of waste dyes in industrial waters becomes more accessible, reducing the impact on the environment and conforms with environmental protection rules on wastewater. 


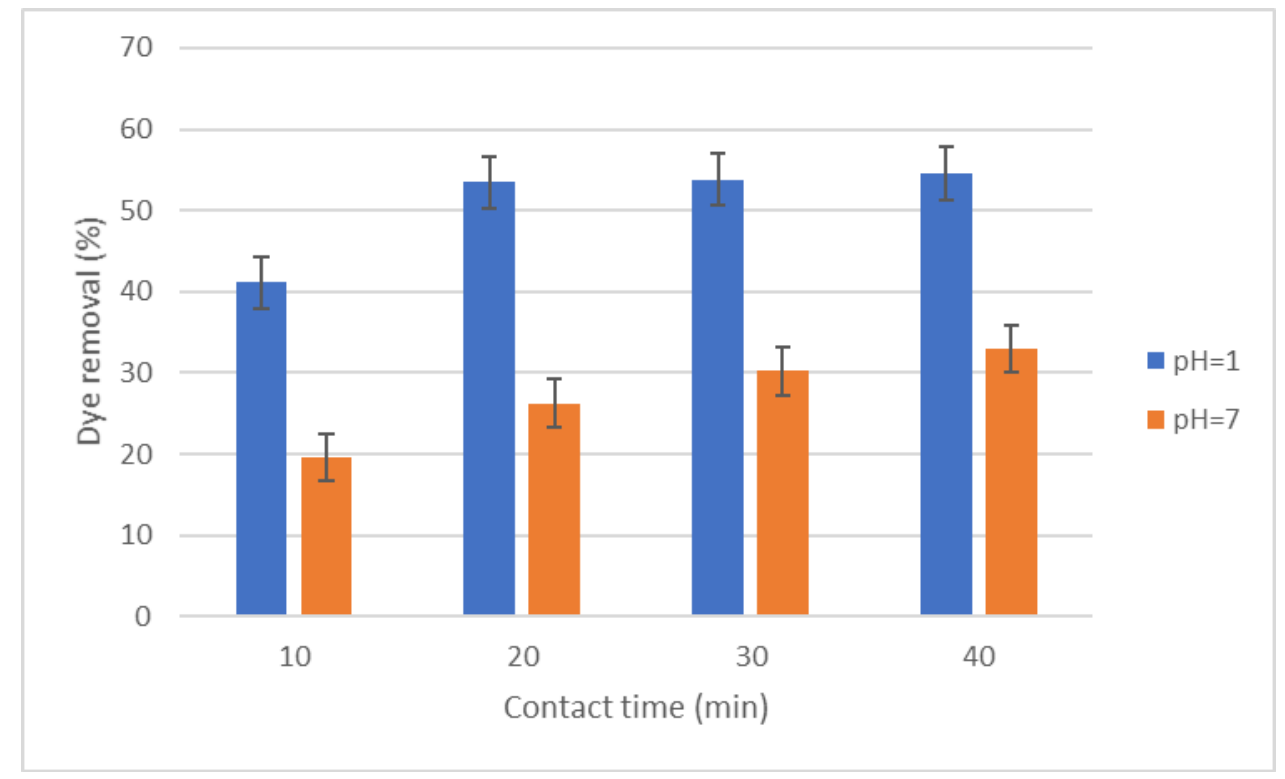

Fig. 7 - Influence of $\mathrm{pH}$ on methyl orange adsorption on grape seeds adsorbent.

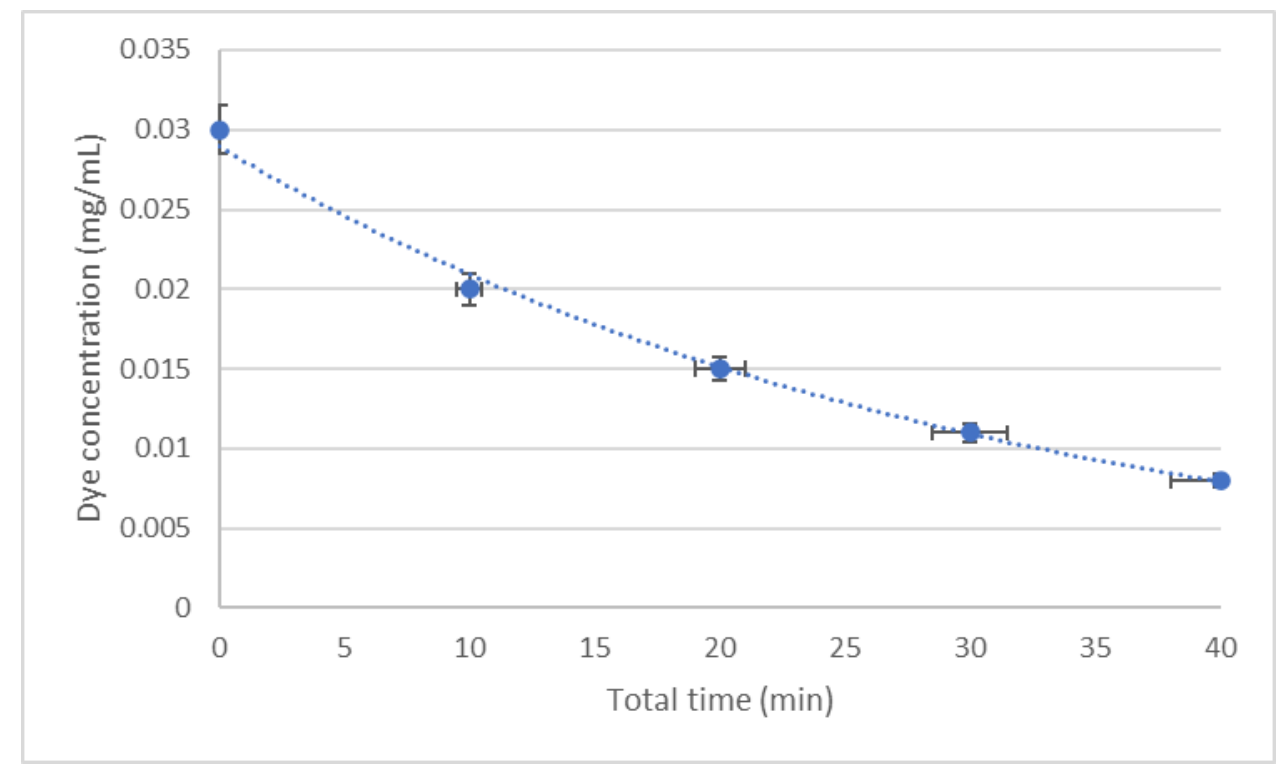

Fig. 8 - Dye concentration variation during stepwise removal of the dye .

\section{CONCLUSIONS}

Aligning with the necessity of efficient and environmentally friendly dye adsorbents, the grape seeds (variety Fetească Neagră) residue, resulted after grapeseed oil extraction, was characterized by means of SEM micrograph, particle distribution and EDX analysis. The grape seed extracted material show specific porosity which makes it a good candidate as dye adsorbent from wastewater resulting from important industry like textile and paper.

Specific factors which influence the adsorbent capacities of the material have been investigated.
Therefore, the influence of contact time, adsorbent quantity and the influence of the solution $\mathrm{pH}$ have been established. The result shows that the adsorbent gives good result at room temperature, making dye removal easy with no important costs.

Nevertheless, the natural adsorbent resulted from grape seed residue have a limited capacity (approx. 50\%) to remove dye from wastewater in one step, it shows better results in a step by step system. These results make it an important candidate of pretreatment of industrial wastewater, removing most of the dye in several steps and reducing the total cost of dye removal to $25 \%$ of initial costs. 


\section{REFERENCES}

1. M. Rafatullah, O. Sulaiman, R. Hashim and A. Ahmad, J. Hazard. Mater., 2010, 177, 70-80.

2. B. Lellis, C. Z. Favaro-Polonio, J. A. Pamphile and J. C. Polonio, Biotechnol. Res. Innov. 2019, 3, 275-290.

3. Z. Yanbo, L. Jian, Z. Yi and L. Yongdi, Environ. Pollut., 2019, 252, 352-365.

4. K. B. Tan, M. Vakili, B. A. Horri, P. E. Poh, A. Z. Abdullah and B. Salamatinia, Sep. Purif. Tehnol., 2015, 150, 229-242.

5. J. C. Coura, D. Profeti and L. P. R. Profeti, Mater. Chem. Phys., 2020, 256, 123711.

6. S. Madduri, I. Elsayed and E. B. Hassan, Chemosphere, 2020, 260, 127683.

7. O. A. Oyewo, E. E. Elemike, D. C. Onwudiwe and M. S. Onyago, Int. J. Biol. Macromol., 2020, 164, 2477-2496.

8. V. Katheresan, J. Kansedo and S. Y. Lau, J. Environ. Chem. Eng., 2018, 6, 4676-4697.

9. A. Azari, R. Nabizadeh, S. Nasseri, A. H. Mahvi and A. R. Mesdaghinia, Chemosphere, 2020, 250, 126238.

10. K. S. Bharathi and S. T. Ramesh, Appl. Water Sci., 2013, 3, 773-790.

11. S.I. Mohammadabadi and V. Javanbakht, Int. J. Biol. Macromol., 2020, 164, 1133-1148.

12. A. A. Awe, B. O. Opeolu, O. S. Fatoki, O. S. Ayanda, V. A. Jackson and R. Snyman, J. Appl. Biol. Chem., 2020, 63, 12.
13. L. Delgado-Moreno, S. Bazhari, G. Gasci, A. Méndez, M. E. Azzouzi and E. Romero, Sci. Total Environ., 2021, $752,141838$.

14. S. Wong, N. A. Ghafar, N, Ngadi, F. A. Razmi, I. M. Inuwa, R. Mat and N. A. S. Amin, Sci. Rep., 2020, 10, 2928.

15. M. Ahmed, F. Mashkoor and A. Nasar, Groundw. Sustain. Dev., 2020, 10, 100322.

16. K. A. Adegoke and O. S. Bello, Water Resour. Ind., 2015, 20, 8-24.

17. OIV and International Organisation of Vine and Wine, "2019 Statistical Report on World Vitiviniculture".

18. Z. Ye, R. Harrison, V. J. Cheng and A. E. D. A. Bekhit, "Wine making by-products" in M. Bordiga "Valorization of wine making by-products", CRC Press, Boca Raton, 2016, 73-115.

19. M. Tociu, M. C. Todasca, M. Mihalache, V. Artem and A. Hanganu, Rev. Chim. (Bucharest), 2018, 69, 130-133.

20. C. Venkitasamy, L. Zhao, R. Zhang and Z. Pan, "Chapter 6 - Grapes" in Z. Pan, R. Zhang, and S. Zicari "Integrated Processing Technologies for Food and Agricultural ByProducts", Academic Press, 2019, 133-163.

21. C. Todasca, D. Gudovan, M. Tociu, R. Trusca, A. I. Nicoara, B. N. Manolescu and F. Manolache, Rev. Roum. Chim., 2020, 65, 69-75.

22. G. Vanni, L. B. Escudero and G. L. Dotto, Water Sci. Tehnol., 2017, 76, 1177-1187.

23. M. Afsharnia, H. Biglari, A. Javid and F. Zabihi, Iran. J. Health Sci., 2017, 5, 48-61. 